\title{
Immunotherapy: The power of perseverance
}

\author{
R. Taylor Ripley, MD, and Reed I. Ayabe, MD
}

\author{
From the Thoracic and Oncologic Surgery Branch, Center for Cancer Research, National Cancer Institute, \\ National Institutes of Health, Bethesda, Md. \\ Disclosures: Authors have nothing to disclose with regard to commercial support. \\ Received for publication Nov 22, 2017; accepted for publication Dec 4, 2017; available ahead of print Jan 6, 2018 \\ Address for reprints: R. Taylor Ripley, MD, Thoracic and GI Oncology Branch, CCR/NCI, Building 10, 4-3952, \\ 10 Center Dr, MSC 1201, Bethesda, MD 20892-1201 (E-mail: R.Taylor.Ripley@gmail.com). \\ J Thorac Cardiovasc Surg 2018;155:1775-6 \\ $0022-5223 / \$ 0.00$ \\ Published by Elsevier Inc. on behalf of The American Association for Thoracic Surgery \\ https://doi.org/10.1016/j.jtcvs.2017.12.002
}

During the past 4 decades, advancements in immunotherapy have revolutionized the treatment of human malignancy. Unlike chemotherapy, with which patients have an improved median survival yet still have poor long-term outcomes, immunotherapy can produce durable complete responses - a "tail on the curve." " The discovery of T-cell growth factor interleukin-2 (IL-2) in 1976 marked the first major breakthrough in modern immunotherapy. Durable complete responses were subsequently noted with this nonspecific immune stimulator in metastatic melanoma and renal cell carcinoma. Additional efforts in the Surgery Branch of the National Cancer Institutes, confirmed that durable responses were achievable with other forms of immunotherapy. Patients who had a complete response after adoptive cell transfer with tumor-infiltrating lymphocytes with lymphocyte-depleting chemotherapy and IL-2 support almost always had sustained tumor regressions. ${ }^{2}$ Although IL-2 and bulk tumor-infiltrating lymphocytes represented major advancements, they were both nonspecific immunologic approaches. Recent efforts to refine or expand the immunologic assault include activating cytotoxic immune cells by silencing checkpoints that downregulate immune cell activation, targeting mutated tumor antigens with engineered T-cell receptors, or targeting "dispensable" antigens such as CD19. Blockage of immunosuppressive checkpoints with cytotoxic T-lymphocyte-associated protein 4 (CTLA-4), programmed death 1 (PD-1), and the PD-1 ligand (PD-L1) represent one mechanistic approach to immunotherapy. ${ }^{3}$ Many of these advances are now helping patients with lung cancer.

Guo and Krupnick ${ }^{4}$ elegantly summarize 3 trials of immune checkpoint inhibitors in non-small cell lung cancer. $^{5,6}$ Guo and Krupnick ${ }^{4}$ note that treatment outcomes were quite different, which may be attributed to heterogeneous PD-L1 expression. In one trial, exploratory analyses suggested that high mutation burden in tumors may also predict improved treatment responses. ${ }^{6-8}$ Guo and Krupnick $^{4}$ speculate further that checkpoint blockade alone often will be insufficient, so combination therapy may be required. What we find remarkable is that there is active

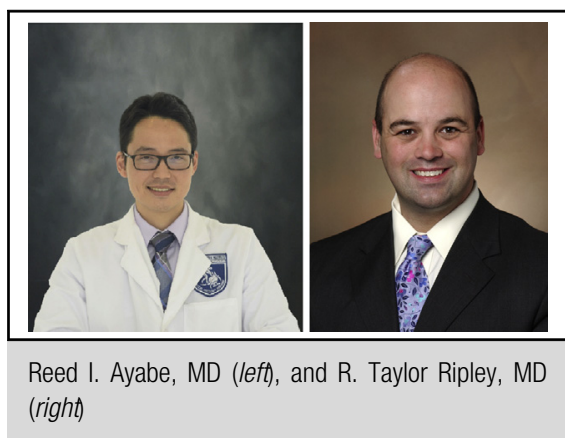

\section{Central Message}

Checkpoint inhibition represents a significant advance in the treatment of NSCLC; however, refinement of this therapy and expansion of immunologic approaches are needed for patients with NSCLC.

See Article page 1771.

discussion of patient selection, mutational and neoantigen burden, and combination therapy in the context of effective immunotherapy. This discussion was not possible 10 years ago, when the only approved immunotherapy for metastatic cancer was IL-2 and no clinical advances in the treatment of lung cancer had yet occurred.

We have had the honor of learning from and working with Dr Steven A. Rosenberg for much of the last decade. He is known to work with an unrelenting perseverance, despite encountering obstacles in his development of effective immunotherapy for cancer. Although we should celebrate recent advances, we need also remember that these advances have been preceded by many failed attempts that did not derail persistent efforts and that these efforts have resulted in effective immunotherapy for lung cancer. Even so, most patients with advanced lung cancer do not survive even after treatment with a checkpoint inhibitor or other targeted therapy. Although much has been achieved, there is still work to be done. We should continue the legacy of pioneers such as Drs Rosenberg, William B. Cooley, James P. Allison, and others by continuing to ask relevant questions and applying a relentless perseverance to improving patient outcomes.

\section{References}

1. Rosenberg SA. IL-2: the first effective immunotherapy for human cancer. J Immu nol. 2014;192:5451-8.

2. Dudley ME, Wunderlich JR, Shelton TE, Even J, Rosenberg SA. Generation of tumor-infiltrating lymphocyte cultures for use in adoptive transfer therapy for melanoma patients. J Immunother. 2003;26:332-42. 
3. Gettinger SN, Horn L, Gandhi L, Spigel DR, Antonia SJ, Rizvi NA, et al. Overall survival and long-term safety of nivolumab (anti-programmed death 1 antibody, BMS-936558, ONO-4538) in patients with previously treated advanced nonsmall-cell lung cancer. J Clin Oncol. 2015;33:2004-12.

4. Guo Y, Krupnick AS. There and back again: an immunotherapy tale. J Thorac Cardiovasc Surg. 2018;155:1771-4.

5. Reck M, Rodríguez-Abreu D, Robinson AG, Hui R, Csőszi T, Fülöp A, et al; KEYNOTE-024 Investigators. Pembrolizumab versus chemotherapy for PD-L1-positive non-small-cell lung cancer. N Engl J Med. 2016;375:1823-33.
6. Carbone DP, Reck M, Paz-Ares L, Creelan B, Horn L, Steins M, et al; CheckMate 026 Investigators. First-line nivolumab in stage IV or recurrent non-small-cell lung cancer. N Engl J Med. 2017;376:2415-26.

7. Nebot-Bral L, Brandao D, Verlingue L, Rouleau E, Caron O, Despras E, et al. Hypermutated tumors in the era of immunotherapy: the paradigm of personalized medicine. Eur J Cancer. 2017;84:290-303.

8. Antonia SJ, Villegas A, Daniel D, Vicente D, Murakami S, Hui R, et al; PACIFIC Investigators. Durvalumab after chemoradiotherapy in stage III non-small-cell lung cancer. N Engl J Med. 2017;377:1919-29. 